\title{
Amor, interdito e transgressão em Rútilo Nada
}

\author{
Francisca Yorranna da Silva ${ }^{\mathrm{i}}$ \\ Mary Nascimento da Silva Leitão ${ }^{\text {ii }}$
}

\begin{abstract}
Resumo: Falar de amor é, na maioria das vezes, evocar um sentimento puro, generoso e justo. Entretanto, a literatura, desde o diálogo platônico entre Sócrates e Diotima, que revela que Eros não é bom nem belo, pois não se trata de um deus, mas de um daimon, até os textos mais contemporâneos, mostra-nos uma face do amor que causa destruição. A culpa disso não está no sentimento em si, mas em ser um amor interdito pelas regras que orientam nossa sociedade e estão arraigadas em discursos fundantes como os religiosos. Assim, este trabalho tem o objetivo de discutir a relação entre amor, interdito e transgressão a partir da leitura comparativa de Rútilo Nada (1993), de Hilda Hilst, e de O erotismo (1987), de Georges Bataille. Por fim, ao concluirmos a análise, esperamos contribuir para a reflexão em torno do tema.
\end{abstract}

Palavras-chave: Amor. Interdito. Transgressão. Hilda Hilst. Rútilo Nada.

\section{Love, interdict and transgression in Rútilo Nada}

\begin{abstract}
To speak about love is, in the most times, to evoke a pure, generous, and fair feeling. However, the literature, since the platonic dialogue between Socrates and Diotima which reveals that Eros is neither good nor beautiful, as he is not a god, but a daimon, until the most contemporary texts, show us one face of love who causes destruction. The blame this is not in the feeling itself, but to be a prohibited love by rules that guide our Society and are rooted in founding speeches like religious. Therefore, this paper has the objective to discuss the relation between love, interdict, and transgression from the comparative reading of Rútilo Nada (1993), by Hilda Hilst, and of $O$ erotismo (1987), by George Bataille. Finally, when we conclude the analysis, we hope to contribute with the reflection about the topic.
\end{abstract}

Keywords: Love. Interdict. Transgression. Hilda Hilst. Rútilo nada.

Submetido em: 29 out. 2020

Aprovado em: 18 nov. 2020

\section{$(c))$ EY-SA}

Esta obra está licenciada com uma Licença Creative Commons

Compartilha Igual 4.0 Internacional

ISSN 1679-6101

DLCV - Língua, Linguística \& Literatura

\footnotetext{
${ }^{\text {i } U n i v e r s i d a d e ~ F e d e r a l ~ d o ~ C e a r a ́ ~(U F C E) . ~ E-m a i l: ~ y o r r a n n a s i l v a @ g m a i l . c o m . ~}$

ii Universidade Federal do Ceará (UFCE). E-mail: maryepoesia@gmail.com.
} 
"Ao contrário do que se supõe, o amor nem sempre aproxima, o amor também desune."

(Raduan Nassar)

\section{VIDA E OBRA DE HILDA HILST ${ }^{1}$}

Escritora brasileira do século XX, Hilda Hilst nasceu em 21 de abril de 1930, na cidade de Jaú, e veio a falecer no dia 04 de fevereiro de 2004, em Campinas, ambas localizadas no interior paulista. Entre uma data e outra, temos um percurso de mais de 70 anos marcados por uma vida e uma escrita transgressoras para os padrões morais e literários da época. Apesar das polêmicas que envolviam o nome de Hilda, a escritora recebeu diversos prêmios e teve, depois de certo tempo, sua obra difundida e bem recebida pela crítica literária de viés acadêmico ou não, seus textos ganharam traduções para o francês, inglês, italiano e alemão, além de adaptações na dramaturgia e na música.

Hilst iniciou sua carreira literária com a publicação de Presságio, em 1950, seguido de Balada de Alzira e Balada do Festival, em 1951 e 1955, respectivamente. Em 1959, lançou Roteiro de silêncio, no qual encontramos o poema "Sonetos que não são", conjunto de seis sonetos que falam sobre a condição feminina do "eu-lírico", que contrapõe os seus desejos às expectativas de seu "amor":

Aflição de ser eu e não outra.

Aflição de não ser, amor, aquela

Que muitas filhas te deu, casou donzela

e à noite se prepara e se advinha

Objeto de amor, atenta e bela.

Aflição de não ser a grande ilha

Que te retém e não te desespera.

(A noite como fera se avizinha).

Aflição de ser água em meio à terra

E ter a face conturbada e móvel.

E a um só tempo múltipla e imóvel

Não saber se se ausenta ou se te espera.

Aflição de te amar, se te comove.

E sendo água, amor, querer ser terra.

(HILST, 1998, p. 383).

\footnotetext{
${ }^{1}$ Os dados biográficos da escritora foram selecionados a partir das informações disponibilizadas no blog "Releituras". Disponível em: http://www.releituras.com/hildahilst_bio.asp. Acesso em: 31 ago. 2020.
} 
Os versos do soneto 1 demonstram o questionamento sobre o que é ser mulher e os papéis sociais que a sociedade, representada no poema pelo amado, espera que ela desempenhe. Desse modo, verificamos que, mesmo inserida em uma tradição literária - a dos sonetistas -, Hilda já começa a romper com essa tradição por não se ater à forma tradicional, que exigiria rimas perfeitas. Além disso, ao invés de cantar apenas a dor da saudade do amado, a poeta coloca as questões da mulher de seu tempo, sobrecarregada pelas expectativas que lhe foram impostas: "Que não se leve a sério este poema/ Porque não fala do amor, fala da pena./ E nele se percebe o meu cansaço/ Restos de um mar antigo e de sargaço." (HILST, 1998, p. 85).

"Sonetos que não são", bem como outros poemas, demonstra que, desde o início, a obra de Hilda Hilst oscilaria entre a tradição e a ruptura tanto de aspectos formais quanto de conteúdo. Tal ruptura é notada, principalmente, nas produções que se seguem às publicadas na década de 1950 e têm seu ápice na prosa dos anos 1980 e 1990. Todavia, cabe ressaltar que antes desse período, Hilda já se destacava pelas experiências com os diversos gêneros. No drama, temos as peças "A possessa" e "O rato no muro", de 1967; bom minha vida "O visitante", "Auto da barca camiri", "O novo sistema" e "As aves da noite", de 1968; e "O verdugo" e "A morte do patriarca", de 1969. Na lírica, os exemplares de Trovas de muito amor para um amado senhor (1959), Ode fragmentária (1961), Sete cantos do poeta para o anjo (1962), Poesia (1959/1967) (1967), Júbilo, memória, noviciado da paixão (1974), Poesia (1959/1979) (1980), Da morte. Odes Minimas (1980) e Cantares de perda e predileção (1980) compõem parte da obra hilstiana. Já Fluxo-floema (1970), Ficções (1977) e Tu não te moves de ti (1980) são os primeiros escritos em prosa de Hilda.

Em 1982, veio a público A obscena senhora D, obra considerada como marco da prosa hilstiana; segundo Ana Lima Cecilio (2018, p.07): "ali estão os mais belos trechos de sua prosa madura, compacta; as construções poéticas, as emoções mais decisivas das personagens; os diálogos mais assertivos [...]”. Nos anos seguintes, Hilst publicou Poemas malditos, gozosos e devotos (1984), Sobre a tua grande face (1986), Com meus olhos de cão e outras novelas (1986) e Amavisse (1989), com o qual se despede da dita "literatura séria" para lançar as obras que constituem o que a própria escritora chamou de "fase obscena" a fim de se tornar mais lida e "ganhar dinheiros" (CECILIO, 2018).

Assim, pertencem a essa "fase obscena" a tetralogia que Hilda chamou de "Pornô Chic", na qual estão inclusos O caderno rosa de Lori Lamby (1990), Contos d'escárnio/ Textos grotescos (1990), Cartas de um sedutor (1991) e Bufólicas (1992). Ainda na década de 1990, a escritora lançou Alcóolicas (1990), Do desejo (1992), Rútilo Nada (1993), Cantares 
do sem nome e de partidas (1995), Estar sendo. Ter sido (1997) e Do amor (1999), encerrando sua careira; "num anúncio límpido e claro [...] ela afirma: 'São tantos livros, mais de quarenta, eu fiz tudo o que pude fazer'." (CECILIO, 2018, p. 7).

Diante de uma produção tão vasta, escolhemos, para fim de análise, Rútilo Nada, a priori definido como conto, mas, no qual, encontramos a fusão de diversos gêneros dentre os quais uma carta e um conjunto de poesias de uma das personagens, imprimindo ao texto e à linguagem com a qual é construído, o caráter transgressor de seus protagonistas e daquela que se expressa através dessas vozes: Hilda Hilst. A autora, que adotou posturas polêmicas e que, assim como sua obra, foi "maldita, gozosa e devota", transpõe os limites da linguagem para recriar os "muros" do interdito a um amor entre dois homens e para dar vazão aos ímpetos da transgressão que movimenta os amantes, bem como toda a humanidade, segundo nos diz Bataille (1987).

Portanto, nosso objetivo, ao discorrer sobre Rútilo Nada, será analisar como os elementos acima mencionados (amor, interdito e transgressão) se imbricam e demonstrar como o amor nem sempre é um sentimento pacífico, antes, pode causar angústias e tragédias na vida dos amantes. Para tanto, pautaremos-nos na comparação de uma visão do erotismo e da linguagem como instrumentos de transgressão a partir da leitura do conto e do que lemos em O erotismo (1987), de George Bataille, bem como de outros textos (literários, filosóficos, religiosos) que sejam pertinentes à discussão.

\section{FUNDAMENTOS DO INTERDITO: OS PRECEITOS DO AMOR}

Sempre que falamos de amor, diversas imagens nos vêm à cabeça. Essas imagens, apesar de diferentes, têm em comum a ideia de bondade, isto é, o amor seria, em sua essência, bom, virtuoso, o mais nobre e sublime dos sentimentos. Talvez isso se explique pela nossa herança cristã, que ver no amor ao próximo e entre um casal o reflexo de como deve ser a comunhão com o Deus que nos amou "de tal maneira que deu o seu filho unigênito para que todo aquele que nele crer não pereça, mas tenha a vida eterna" (Jo.3.36). Entretanto, na epígrafe que abre a narrativa de Rútilo Nada, encontramos a ideia oposta ao que inúmeras vezes nos foi dito: "o amor é duro e inflexível como o inferno"2.

\footnotetext{
${ }^{2}$ Frase atribuída à Teresa Cepeda e Ahumada, ou Santa Teresa de Ávila, e colocada por Hilda Hilst como epígrafe de seu conto.
} 
Ao colocar essa sentença na "abertura" de seu texto, Hilda Hilst nos leva a questionar sobre a essencial bondade do amor, característica que se afirmou através de um dos discursos mais famosos feito pelo apóstolo Paulo, no qual ele nos diz que:

O amor é sofredor, é benigno; o amor não é invejoso; o amor não trata com leviandade, não se ensoberbece. Não se porta com indecência, não busca os seus interesses, não se irrita, não suspeita mal; Não folga com a injustiça, mas folga com a verdade; Tudo sofre, tudo crê, tudo espera, tudo suporta. (I Co.13.4-7)

Ao lermos a sentença da epígrafe, é quase automática a retomada do fragmento bíblico, ainda que seja para contestá-lo, de forma que, desde o início do conto, o amor estará ligado ao trágico e poderá levar os amantes à ruína. Esse indicativo é confirmado tão logo adentramos o texto:

OS SENTIMENTOS VASTOS não têm nome. Perdas, deslumbramentos, catástrofes do espírito, pesadelos da carne, os sentimentos vastos não têm boca, fundo de soturnez, mudo desvario, escuros enigmas habitados de vida, mas sem sons, assim eu neste instante diante do teu corpo morto. Inventar palavras, quebrá-las, recompô-las, teria sido preciso, Lucas meu amor, meus 35 anos de vida colados a um indescritível verdugo, alguém Humano, e há tantos indescritíveis Humanos feitos de fúria e desesperança, existindo apenas para nos fazer conhecer o nome da torpeza e da agonia" (HILST, 1993, p. 85).

Lucius Kod, um dos protagonistas do conto, começa a contar como ele chegara até aquele momento; à voz dele sucedem-se outras que, embora fragmentadas, compõem o todo da narrativa. Decifrando esses "escuros enigmas" que são as falas dos narradores, conhecemos a trama que unira os caminhos de Lucius e Lucas, apresentados quando este inicia um namoro com a filha daquele, ou seja, a primeira forma de ligação entre os amantes é de sogro e genro. A paixão entre eles cresce de forma velada, porém, com o tempo, a relação começa a levantar suspeitas e tem no pai de Lucius o principal opositor, que irá até as derradeiras consequências para assegurar que a interdição não seja violada.

Essa interdição se dá não apenas pelo parentesco, mas, principalmente, por se tratar de uma relação homoerótica que, apesar de já ter sido aceita em sociedades antigas, ainda hoje, é considerada "proibida" sob a ótica da moral patriarcal no Ocidente, a qual se fundamentou nos dogmas judaico-cristãos instituídos pelas leis do pentateuco - "Não te deitarás com um

\footnotetext{
${ }^{3}$ Nesta citação, especificamente, optamos por usar a edição Almeida Corrigida Fiel da Bíblia, cuja versão online se encontra disponível em: https://www.bibliaonline.com.br/acf/1co/13. Acesso em: 31 ago. 2020. A escolha diz respeito ao fato de, por se tratar de uma versão mais antiga, não haver distinção semântica entre "amor" e "caridade", o que acontece em edições mais recentes.
} 
homem como se deita com uma mulher. É uma abominação.” (Lv.18.22) -, ou ainda, nas doutrinas do apóstolo Paulo: "igualmente os homens, deixando a relação natural com a mulher, arderam em desejo uns para com os outros, praticando torpezas homens com homens e recebendo em si mesmos a paga da sua aberração.” (Rm.1.27). Desta forma, seja no Antigo ou Novo Testamento, as leis que orientam judeus e cristãos são severas e preveem que a transgressão do interdito ao homoerotismo seja punida:

Não sabeis que os injustos não herdarão o reino de Deus? Não vos enganeis: nem os devassos, nem os idólatras, nem os adúlteros, nem os efeminados, nem os sodomitas, nem os ladrões, nem os avarentos, nem os bêbedos, nem os maldizentes, nem os roubadores herdarão o reino de Deus. (I Co.6.9-10).

Observemos que, no excerto bíblico, a alusão ao homoerotismo, através dos termos "efeminados" e "sodomitas", tem, talvez, o intuito de abranger duas formas diferentes de manifestação da homoafetividade; na primeira, está implícita uma questão de gênero além da prática sexual, o que não ocorre na segunda, que se atém ao exercício da sexualidade. Não obstante essa diferenciação, não iremos nos aprofundar no assunto tendo em vista não se tratar do foco deste trabalho, todavia, essa ressalva demonstra o peso que o patriarcalismo exerce nas diversas religiões, dentre as quais, o cristianismo é exemplo, ainda que a verdadeira lei dessa religião devesse ser o amor, independentemente de sua forma de expressão:

Os fariseus, ouvindo que ele fechara a boca dos saduceus, reuniram-se em grupo e um deles - a fim de pô-lo à prova - perguntou-lhe: "Mestre, qual é o maior mandamento da Lei?" Ele respondeu: Amarás a Deus de todo o teu coração, de toda a tua alma e de todo o teu espírito. Esse é o maior e o primeiro mandamento. O segundo é semelhante a esse: Amarás o teu próximo como a ti mesmo. "Desses dois mandamentos dependem toda a Lei e os Profetas". (Mt.22.34-40).

A contradição do cristianismo ter como base o amor e, ao mesmo tempo, coibir algumas das suas manifestações, explica-se pela íntima relação com o patriarcalismo, que vê em qualquer união que não seja heteronormativa uma ameaça à ordem social e à preservação da espécie, de modo que, não por acaso, dentre outros interditos sexuais, estejam as relações que não têm como finalidade primeira a procriação ou representem um risco à descendência, como nos casos de incesto (FREUD, 2013).

Destarte, se determinadas formas do sentimento amoroso não são aceitas em sociedade, elas passam a pertencer à esfera do interdito, que, por sua vez, formam o que Sigmund Freud denominou de "totens e tabus", e qualquer forma de violação a esses 
elementos regulativos é passível de punição, uma vez que "[...] a violação de determinados tabus envolve um perigo social, que tem de ser conjurado ou expiado por todos os membros da sociedade, a fim de não prejudicar a todos" (FREUD, 2013, p.28), pois, "Deixando impune a violação, os outros se dariam conta de querer agir da mesma forma que o transgressor" (FREUD, 2013, p. 28-29).

Por outro lado, só a proibição em si, mesmo que acompanhada de sanções caso sejam violadas, não é suficiente para evitar que os homens das mais variadas épocas e lugares tenham sido e continuem sendo transgressores, posto que estão submetidos a dois movimentos: "[...] o terror que intimida, e a atração, que comanda o respeito fascinado. $\mathrm{O}$ interdito e a transgressão respondem a esses dois movimentos contraditórios: o interdito intimida, mas a fascinação introduz a transgressão.” (BATAILLE, 1987, p. 45). Abre-se, então, um vasto campo para a transgressão no qual o amor, ao contrário do que nos diz outros discursos, seria, essencialmente, transgressor.

\section{FUNDAMENTOS DO INTERDITO: OS MUROS DA LINGUAGEM}

Para entendermos como se estabelece o diálogo entre o que nos é narrado em Rútilo Nada e a perspectiva abordada por George Bataille em O erotismo (1987), é necessário pensarmos sobre o que nos constitui enquanto seres humanos, ou seja, aquilo que nos distingue dos animais. Segundo Bataille, o princípio fundante de nossa humanidade está na nossa capacidade de elaborar um conjunto de proibições que normatizam nosso comportamento diante da morte e do sexo: "Paralelamente, eles se impuseram restrições conhecidas como interditos. Essas interdições essencialmente - e certamente - recaíram sobre a atitude para com os mortos. É provável que elas tenham tocado ao mesmo tempo ou pela mesma época - a atividade sexual." (BATAILLE, 1987, p. 20-21). Desta forma, nossos principais interditos dizem respeito ao modo como lidamos com o que está na origem da vida - o ato sexual - e no fim dela - a morte. O embate é antigo conhecido e já fora formulado através da oposição "pulsão de vida versus pulsão de morte”, respectivamente representadas por Eros e Tanatos:

Sigmund Freud (1856-1939) argumentou que essa relação é influenciada por fatores ou energias inatas que pressionam o organismo para uma descarga: as pulsões, descrevendo duas delas como antagônicas [...] A pulsão de natureza sexual, com tendência à preservação da vida - denominada por ele de Eros e o seu antagônico (Tanatos), uma pulsão que levaria à segregação de tudo o que é vivo, à destruição, à morte. Ambas as pulsões nunca agem de forma 
isolada, pois que estão sempre trabalhando em conjunto. (RODRIGUES, 2010, p. 16).

Neste sentido, é possível afirmar que o interdito está para a pulsão de vida e a transgressão para a pulsão de morte, pois a quebra dos paradigmas que são estabelecidos pelas interdições resultaria no desequilíbrio da ordem social em que vivemos, isto é, no caos. Todavia, se o interdito assegura a vida que, por sua vez, está associada a Eros, como o erotismo pode ser considerado um instrumento de transgressão? A resposta é dada, novamente, por Bataille: $\mathrm{O}$ conhecimento do erotismo, ou da religião, exige uma experiência pessoal, igual e contraditória, do interdito e da transgressão (BATAILLE, 1987, p. 24).

Assim, acreditamos que o impulso erótico é um movimento que traz vida, mas, também pode acarretar a dissolução absoluta, ou seja, a morte. A ambiguidade é confirmada ao verificarmos que essa capacidade destrutiva está ligada à manutenção do interdito, pois preservá-lo significa aniquilar aqueles que o violaram, conforme acontece com os amantes em Rútilo Nada, que são atingidos pela fúria daqueles que os cercam:

[...] e eu Lucius Kod neste agora me sei mais uma esquálida cadela, a morte e não a vida escoando de mim, musgos finos pendendo dos abismos, estou caindo e ao meu redor as caras pétreas, quem são? amigos? minha filha adolescente? teus jovens amigos? Caras graníticas, ódio mudo e vergonha, palavras que vêm de longe, evanescentes mas tão nítidas como fulgentes estiletes, palavras de supostos éticos Humanos:

Constrangedor Louco Demente

Absurdo Intolerável [...]

(HILST, 1993, p. 86).

Apesar de a maior violência ter sido dirigida a Lucas, afinal estamos diante de seu corpo morto, Lucius também é alvo dessa violência que se manifesta não mais fisicamente, mas, agora, através do "ódio mudo" e da "vergonha" que se expressa nas "caras graníticas" e nas "palavras que vêm de longe". Logo, os adjetivos em destaque - constrangedor, louco, demente, absurdo, intolerável - compõem a sanção negativa que Lucius e seu amor por Lucas sofrem por parte daquelas pessoas. O uso dessas palavras também é símbolo da relação que se estabelece entre interdito e linguagem, uma vez que, enquanto Lucius não consegue descrever sua dor, precisando recorrer à imagem de uma "esquálida cadela"; as personagens definidas como "éticos Humanos" se utilizam da linguagem para colocar Lucius e Lucas à margem da sociedade.

Neste sentido, assim como o mundo passou a existir por meio da palavra e a “invenção" da escrita consolidou a diferença entre o que foi/é a História e a Pré-História, o 
interdito é trazido à consciência dos homens pela linguagem, seja dos ritos ou dos dogmas religiosos, e divide a experiência humana em dois estágios: o primeiro, como o nome diz, é um estado primitivo, ligado à animalidade ou à natureza; o segundo, orientado pelas normas sociais, é o que chamamos de estado de cultura ou de civilização.

Em Rútilo Nada, é notório que tanto Lucius quanto Lucas lidem com a linguagem e que, quando se encontram, essa linguagem seja posta em xeque:

Minhas frases emboladas, não nada tudo bem só estava concentrado hein? não não sim sou jornalista, sim, comentários políticos, resenhas sobre ensaios, às vezes literatura sim, poesia? não nunca, poesia já é mais complicado.

Lucas faz História na universidade, pai, mas adora poesia, escreve poemas sobre muros

você quer dizer os poemas nos muros?

não não, falo de muros nos meus poemas [...]

(HILST, 1993, p. 88).

A cena que descreve como os amantes se conhecem é bastante singular, visto que a confusão de Lucius é revelada através de suas "frases emboladas", isto é, ainda que por instante mínimo, Kod "perde" a linguagem, pois, tal como a dor da perda, o arrebatamento causado pela paixão que o invade naquele momento é um sentimento vasto e, portanto, sem nome. Essa breve ausência da linguagem demonstra, também, que, infimamente, os interditos são colocados em suspenso para dá lugar à transgressão impulsionada pelo desejo erótico, uma vez que, "O erotismo do homem difere da sexualidade animal justamente no ponto em que ele põe a vida interior em questão. O erotismo é na consciência do homem aquilo que põe nele o ser em questão.” (BATAILLE, 1987, p. 20).

Destarte, o encontro entre amante e amado despertam ambos para a reflexão de quem eles são e o resultado dessa epifania é a constatação de que, até ali, não haviam sido plenos de suas subjetividades; ao contrário, haviam sido apenas projeções dos interditos:

Posso deduzir que escapei da casca consistente, que eu estava encerrado ali, não, que o meu corpo era o fruto da paineira, todo fechado, e num instante, abriu-se. Abriu-se por quê? Porque já era noite para mim e aquele era meu instante de maturação e rompimento. Porque fui atingido pela beleza como se um tigre me lanhasse o peito. (HILST, 1993, p. 87-88).

A metáfora utilizada por Lucius para descrever como se sente diante de Lucas é bastante significativa, posto que, ao imaginar-se como um fruto prestes a romper com a casca que o aprisiona, ele reitera a força do erotismo que o domina naquele momento e que ele compara a um golpe desferido por um tigre, animal de grande porte, feroz e, ao qual, se 
atribui extrema sensualidade. Logo, entendemos que não é qualquer desejo que o atinge, porque somente um desejo violento seria capaz de romper a "casca consistente" da persona que ele elaborou de acordo com os interditos sociais durante seus 35 anos: "Pela primeira vez o meu olhar encontrava a junção do nojo e da beleza. Pela primeira vez em minha vida, eu, Lucius Kod, 35 anos, suguei o sexo de um homem. Deboche e clarão na lisura da boca." (HILST, 1993, p. 96).

\section{FUNDAMENTOS DA TRANSGRESSÃO: A LINGUAGEM ALÉM DOS MUROS}

Durante 35 anos, Lucius Kod havia se escondido atrás dos muros dos papéis sociais que lhe foram impostos: filho de banqueiro, jornalista, pai, marido. Foi somente com a descoberta da paixão por Lucas, que foi, simultaneamente, a descoberta de si, que ele transpôs esses muros. Todavia, ainda ligados às imposições que os aprisionavam, os amantes optam por manter a relação em segredo, decisão que não impede que pessoas próximas à família e, principalmente, o pai de Lucius passem a olhá-los com desconfiança: "mais claro é o que ando vendo, Lucas e você, afaste-se desse rapaz, me olha, Lucius, me olha, esse rapaz é o namorado da tua filha, o que é que você fala tanto com esse rapazola? amigos meus te viram várias vezes com ele nas ruas, nos bares" (HILST, 1993, p. 93).

As ordens do pai de Lucas configuram o exercício da autoridade patriarcal na sociedade, reprimindo toda forma de união que não se paute na heterossexualidade, ou seja, na formação de um casal que tenha como base um homem e uma mulher. Sabemos, contudo, que essa prerrogativa acaba sendo um jogo de hipocrisia, pois esse modelo de casal e, na maioria das vezes, de família, satisfaz apenas as exigências do conservadorismo econômico, político e moral. É o caso do pai de Lucius:

Desfigurado meu pai na madrugada, o roupão de seda, listas negras, que elegância meu pai na madrugada, o roupão creme de seda e finas listas negras, a boca trêmula, apagada no giz da própria cara: então anos de decência e luta por água abaixo e eu um banqueiro, com que cara você acha que eu vou aparecer diante de meus amigos, ou você imagina que ninguém sabia, crápula, canalha, tua sórdida ligação, e esse moleque bonito era o namoradinho da minha neta, então vocês combinaram seus crápulas, aquele crapulazinha namorou minha neta para ficar perto de você. gosta de cu seu canalha? gosta de merda? fez-se também de mulherzinha com o moço machão? ele só pode ter sido teu macho porque teve a decência de se dá um tiro na cabeça, mate-se também seu desgraçado mate-se (HILST, 1993, p. 87). 
O excerto permite que conheçamos quem era o pai de Lucas: um homem elegante, um banqueiro, pertencente à elite e com uma reputação a zelar. Assim, a apreensão com as consequências da relação entre Lucius e Lucas se deve, sobretudo, ao risco de ter seu nome e seus negócios prejudicados por um escândalo, e não por motivos afetivos, como a suposta preocupação com a neta. No trecho, notamos, ainda, que o pai de Lucius os categorizam sob a ótica binarista que atribui determinados comportamentos ao gênero masculino e outros ao feminino, de modo que, um ato de "coragem" como o suicídio é tido por ele como coisa de "macho", o que, consequentemente, faz de Lucius uma "mulherzinha". Além disso, os adjetivos "crápula", “canalha” e "moleque”, por exemplo, denotam a visão negativa atribuída aos amantes e reforçam o papel da linguagem na afirmação do interdito.

O fragmento também é importante por esclarecer a causa da morte de Lucas e por nos fazer indagar o que motivaria um suicídio; a revelação vem com a leitura de uma carta que Lucas deixou ao seu amante, na qual conta que sofrera diversas agressões, chegando a ser estuprado por dois homens desconhecidos. O choque causado no leitor é ainda mais intenso quando descobrimos que fora o pai de Lucius o mandante do crime: "Teu pai veio ver o serviço, Lucius. Saiu há pouco. A porta ficou entreaberta. Sentou-se na beirada da cama. Passou a unha ao longo da minha espinha. vai ter tudo comigo, moço. Afaste-se de meu filho.” (HILST, 1993, p.98). A confissão de Lucas nos faz perceber que o pai de Lucius, embora empenhado em esconder o filho e a si dentro dos muros do interdito, acaba se deixando levar pelo desejo de possuir Lucas tal qual Lucius fizera.

posso te tocar menino?

Eu estava de bruços e suspendi a cabeça para ver.

A boca do teu pai tremia.

Ele beijou minha boca ensanguentada. Eu sorri. De pena da volúpia.

(HILST, 1993, p. 99).

Os acontecimentos narrados por Lucas na carta expõem uma face do pai de Lucius que, até então, desconhecíamos, porque, inserido em um sistema opressor, ele também havia se encarcerado em seus próprios muros e, semelhante ao que acontecera com Lucius, só o encontro com Lucas trouxe à tona os desejos reprimidos em seu inconsciente, embora de forma menos violenta, pois, a discussão que Lucius tem com o pai na madrugada do velório demonstra que o banqueiro voltara a usar as máscaras que lhe cabiam.

Não obstante esse retrocesso, destacamos o papel de Lucas na narrativa, uma vez que ele desperta as pulsões eróticas de Lucius e seu pai, impulsionando-os a transgredir. Nessa 
perspectiva, inferimos que Lucas é a personagem marcada mais intensamente pelo signo da transgressão, mesmo que ele tenha consciência dos muros que o cercam:

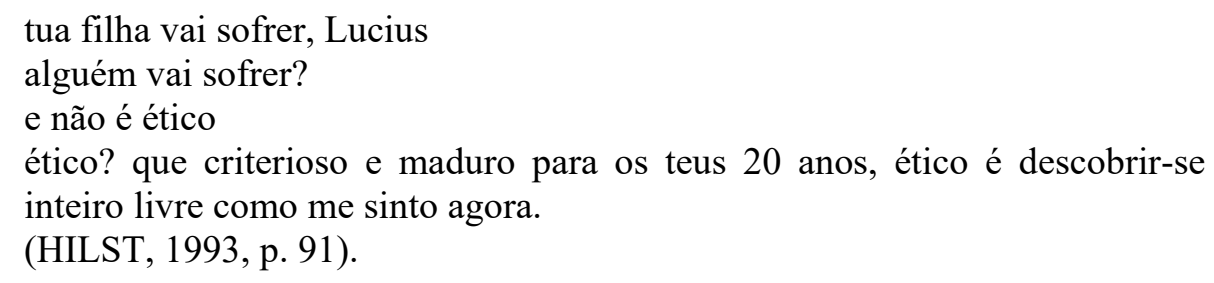

Lucas sabe que sua relação com Lucius fere os princípios éticos, se considerarmos ética como sinônimo de moral, o que é questionável para Lucius, pois, uma vez "inteiro livre", não poderia retornar ao estágio anterior ao que foi tocado pela beleza do amado. Porém, não seria tão simples para os amantes se desvencilharem das amarras do interdito que se consolidam, sobretudo, na linguagem. Assim, se por um lado Lucius quer aderir a uma nova ética fundada em seu amor por Lucas, por outro, ele descreve o momento da união sexual como uma fusão de "nojo e beleza", "deboche e clarão", constituindo uma aura de decadência em torno deles, de modo que, os amantes, a partir dali, estarão sempre guiados pelos movimentos de queda e de ascensão. São os impulsos de vida e morte que norteiam a ideia de erotismo que, por sua vez, funda-se no interdito e na transgressão.

Desta forma, quando Lucas tenta colocar a ética acima de seus desejos, ele está usando a razão para "preservar" sua vida, mas, também, está sendo impelido pelos sentimentos, pois reconhece a existência da paixão que o levará à morte. Essa autoconsciência, para Bataille, constitui uma experiência de prazer no interdito:

Devemos, podemos saber exatamente que os interditos não são impostos de fora. Isto nos aparece na angústia, no momento em que transgredimos o interdito, sobretudo no momento suspenso quando ele ainda atua e que, mesmo assim, cedemos ao impulso a que ele se opunha. Se observamos o interdito, se a ele nos submetemos, não temos mais consciência dele. Mas sentimos no momento da transgressão, em si, a angústia sem a qual o interdito não existiria: é a experiência do pecado. A experiência leva à transgressão realizada, à transgressão bem sucedida que, sustentando o interdito, sustenta-o para dele tirar prazer. (BATAILLE, 1987, p. 25-26).

Portanto, a tentativa de Lucas em respeitar o interdito nada mais, mesmo que inconscientemente, nada mais é do que uma forma de chegar à transgressão, o que sabemos que acontece através das memórias de Lucius e dos relatos deixados por Lucas em sua carta de despedida: 
Quando nos beijamos naquela antiquíssima tarde, a consciência de estar beijando um homem foi quase intolerável, mas foi também um sol se adentrando na boca, e na luz desse sol havia uma friez de água de fonte, uma diminuta entre as rochas, e beijei tua boca como qualquer homem beijaria a boca do riso, da volúpia, depois de anos de inocência e austeridade. (HILST, 1993, p. 99).

O ponto de vista de Lucas sobre a experiência amorosa é repleto de sentidos e reitera o que Bataille afirma sobre a angústia no momento de transgredir o interdito; de acordo com o jovem, "a consciência de estar beijando um homem foi quase intolerável". Esse sentimento, talvez, seja um presságio do que vem após o excesso cometido, isto é, uma vez dominados pela paixão e consumado o desejo, momento de ascensão para os amantes, o passo seguinte é a queda. O abismo que se abre e separa amante e amado é explicado, quem sabe, na própria origem de Eros que conjuga em sua natureza as principais características dos pais, a demasia e a falta:

Na qualidade de filho de Poros e Penia, coube-lhe uma sorte semelhante a deles. Em primeiro lugar, está sempre na penúria e está longe de ser, como a maioria o imagina, delicado e belo: pelo contrário, é rude e enrugado, anda descalço e não tem lar; deita-se constantemente sobre a terra nua, pois não dispõe de um leito, descansando junto às soleiras das portas e às margens das estradas ao ar livre; coadunando-se com a natureza de sua mãe, permanece convivendo sempre com as privações. Entretanto, assemelhando-se a seu pai, é um planejador que visa a tudo que é belo e bom e, de fato, ele é corajoso, impetuoso e intenso, um admirável caçador, o tempo todo urdindo estratagemas; desejoso e amante da sabedoria, passa a vida em busca do entendimento; [por outro lado,] é mestre da prestidigitação, com as poções e o discurso artificioso. (PLATÃO, O Banquete, 203c-e).

A ambiguidade inerente ao deus do amor, nesse sentido, afetaria de igual modo aqueles que estão sob o seu domínio, fato que se expressa na angústia que antecipa o fim da plenitude que amante e amado desfrutam juntos. No caso dos amantes de Rútilo Nada, a sensação de queda parece antecipar algo mais terrível e do qual Lucas tem conhecimento: "Não devo sobreviver a mim mesmo. Sabes por quê? Parodiando aquele outro: tudo o que é humano me foi estranho." (HILST, 1993, p. 103).

Lucas está certo. Infelizmente, ele não sobrevive à estranheza imposta por aqueles que Lucius chamou, ironicamente, de "éticos Humanos". Lucius e Lucas recusam essa ideia de humanidade fundada no interdito e escolhem a via da transgressão como ascese, porém, esse caminho alternativo os leva à ruína: "Há alturas soberbas/ Danosas, se tocadas./ Como a tua própria boca, amor,/ Quando me toca." (HILST, 1993, p. 103). Os versos do poema "VI" anunciam a potencial dissolução que os espera, em primeiro plano, no próprio ato erótico em 
que seus corpos se fundem e tornam-se unos - "Te seguindo sigo apenas a mim mesmo" (HILST, 1993, p.95) -; em segundo, quando Lucas morre.

\section{CONSIDERAÇÕES FINAIS}

A morte de Lucas confere o aspecto trágico à narrativa de Rútilo Nada e corrobora com a tese que se expõe na epígrafe da obra, a de que "o amor é duro e inflexível como o inferno"; pensamento que também é encontrado em $O$ erotismo, de George Bataille. Segundo o filósofo, o impulso erótico é dotado tanto de pulsão de vida quanto da pulsão de morte e, portanto, pode provocar danos irreparáveis como os que sofrem Lucius e Lucas, indivíduos banidos da esfera "humana" pela morte ou pela perda da linguagem ou, pelo menos, de um tipo dela, posto que a transgressão funda outra linguagem, a da poesia. Logo, se é no texto poético que se encontra a transgressão por excelência, Lucas não poderia ser outra coisa senão poeta, deixando sua marca na narrativa que derruba os muros da prosa para se tornar poesia, ultrapassa os limites do conto para ser carta e poema, que sem abrir mão da unidade, define-se na multiplicidade - de vozes, de textos, de gêneros.

Nessa perspectiva, não podemos esquecer que a narrativa de Lucius Kod e Lucas se materializa, pela linguagem, na escrita também transgressora de Hilda Hilst, mulher que ousou romper com seus próprios interditos - morais e literários - para sobreviver a si mesma e ao mundo.

\section{REFERÊNCIAS}

BATAILLE, George. O erotismo. Tradução: Antonio Carlos Viana. Porto Alegre: L\&PM, 1987.

BÍBLIA ONLINE. Disponível em: https://www.bibliaonline.com.br/acf. Acesso em: 31 ago. 2020.

CECÍLIO, Ana Lima. A obscena senhora H. In: CECÍLIO, Ana Lima; ABREU, Caio Fernando; HILST, Hilda. Três vezes Hilda: biografia, correspondência e poesia. São Paulo: Companhia das Letras, 2018. p. 5-11.

FREUD, Sigmund. Totem e tabu: algumas concordâncias entre a vida psíquica dos homens primitivos e dos neuróticos. São Paulo: Penguin Classics; Companhia das Letras, 2013.

HILST, Hilda. Rútilo Nada. Campinas: Pontes, 1993. 
PLATÃO. O banquete. In: PLATÃO. Diálogos: O banquete; Mênon (ou da virtude); Timeu; Crítias. Tradução, textos complementares e notas Edson Bini. Bauru, SP: Edipro, 2010. p. 33107.

RODRIGUES, Ivon Rabelo. Entre o escuro e a rutilância: as armadilhas de Eros e Tanatos em duas narrativas de Hilda Hilst. 2010. Dissertação (Mestrado em Literatura e Interculturalidade) - Universidade Estadual da Paraíba, 2010. 